\title{
O renascimento de uma cultura perdida
}

\author{
BÉATRICE PICON-VALLIN
}

TRADUÇÃO:

JOICE AGLAE BRONDANI

MARINA PELLE Especialista do teatro russo e autora de várias obras traduzidas em diversas línguas. Diretora de pesquisa no
Centro Nacional de Pesquisa Científica (CNRS, ARIAS). Dirigiu o Laboratório de Artes do Espetáculo e foi profes-
sora de história do teatro no Conservatório Nacional de Arte Dramática, em Paris, até 2008. Dirige três coleções:
Arts du spcetacle pela CNRS Edições, th XX pela L'Age d'Homme e Mettre en scène pela Actes Sud-Papiers.
Leciona em inúmeras escolas e institutos de teatro, na França e no exterior.

Professora PRODOC-CAPES - PPGA-UFU. Doutora pelo PPGAC-UFBA (intercâmbio Università di Roma Tre e Scuola Sperimentale del'Attore-ITA). Mestre pelo PPGAC-UFBA (intercâmbio Université Paris X-FRA). Fundadora da Cia Buffa de Teatro (BRA) e Bottega Buffa CircoVacanti (ITA). Atriz e diretora teatral, integrou o elenco de clowns no espetáculo SlavaSnowShow, na temporada do Théâtre Casino, em Paris, em 2011. Idealizadora do projeto de pesquisa "Teatro-Máscara-Ritual" (2010-).

Bacharel em Artes Cênicas - Interpretação, pela Universidade Federal de Santa Maria. Mestre em Arts du Spectacle pela Université Paris VIII-Saint-Denis. Reside na França desde 2005, atua em diferentes espetáculos das Compagnias France In Vivo, Aurore, entre outras.

${ }^{*}$ In: Le corps en jeu. Dir. O. ASLAN. Paris: CNRS Editions, 1993. 1a ed. 
Este surgimento lúcido do corpo mal colocado, na dramaturgia, indica a tomada de consciência do grau de degradação, tanto física quanto moral, do indivíduo e da sociedade. Por sua vez, atores redescobrem o corpo humano como meio de expressão total, trabalho que procede, ao mesmo tempo, de uma rejeição global da instituição, do rígido sistema stanislavskiano a eles impostos, e de um desejo de relações humanas diferentes, isto é, através de uma comunidade artística organizada em torno de uma pesquisa que comprometa arte e vida. Com ou sem palavras, discurso sobre o corpo ou discurso do corpo, encontramos o mesmo desejo de sinceridade e de contato.

Este teatro de pantomima é mais amplamente nominado no início dos anos oitenta, em razão da abrangência do movimento, como "teatro plástico"1, em oposição à tradição psicológica. Sua emergência progressiva descreve uma história paralela a do teatro soviético, crônica sinuosa de artistas de rua-pesquisadores cuja genealogia, em curto prazo, começa após o Festival da Juventude de 1957, em Moscou, o qual marca a primeira abertura pós-stalinista do meio teatral: Robert Ligers em Riga, Rudolf Slavski em Leningrado e llia Rutberg em Moscou. Este último é um dos fundadores, juntamente com M. Razovski e A. Axelrod, do Estúdio amador Nach Dom na Universidade de Moscou, em 1959, onde seu primeiro espetáculo de pantomima é interditado ${ }^{2}$. Por volta de 1968, em Kaunas, surge uma comunidade teatral em torno do Estúdio de pantomima de Modris Tennison, aluno de Ligers.

Com as fronteiras que se abrem, o público soviético recebe, após o Berliner Ensemble, a commedia dell'arte, o teatro oriental - turnês de Arlequim servidor de dois Patrões do Piccolo Teatro de Milão, em 1960, e de um teatro de kabuki, em 1961 -, em $1964^{3}$ acolhe Marcel Marceau no Teatro Na zábradlí, o teatro africano ${ }^{4}$. Alguns teatros profissionais da URSS, sobretudo Taganka, desde a criação de $A$ alma boa de Se-Tzuan (1963), insistem sobre "a forma". Culpada e difamada ${ }^{5}$, eles se interessam pelo "despertar do corpo" através de um treinamento físico inspirado por antigos atores de Meyerhold ${ }^{6}$, sobre o qual aparece, enfim, em 1967, um grande volume de lembranças. Sujeito a uma série de perseguições, o coreógrafo Leonid Jakobson causa um escândalo no Teatro Kirov de Leningrado ao abandonar as pontas e alterando ironicamente o vocabulário da dança clássica: introdução de movimentos pantomímicos ou esportivos, de argumentos tirados de peças de Maiakovski (Mystère-Bouffe, 1962), de poemas de Blok (Les Douze, 1964) ou da obra esculpida de Rodin (1958) .

1 V. ŠČERBAKOV. À Propos de théâtre plastique in: Teatr, n. 7, Moscou. 1985, p. 33-35.

2 Cf. Les Voies de la création théâtrale. v. XII. Paris: Edições do CNRS, col. Arts du Spectacle, 1984, p. 191-192. Rutberg mostrará várias pantomimas para A Resistível Ascensão de Arturo Ui de B. Brecht no Estúdio do MGU (Universidade do Estado de Moscou), direção de M. Zakharov e S. loutkevitch, em 1964.

3 As turnês destas duas últimas trupes aconteceram em 1964. Foi no Teatro Na zábradlí, inaugurado em 1958, em Praga, que se produziu o diretor e mimo L. Fialka, altamente influenciado por M. Marceau. Sobre Marceau, cf. em russo, E. MARKOVA. M. Marceau. Leningrado: Iskusstvo, 1975.

4 Cf. M. ROZOVSKIJ. Režisser zrelišča Mettre en scène un spectacle Encenar um espetáculo. Moscou, 1972, p. 69.

5 A caça aos formalistas começou em 1936.

6 Cf. I. LIOUBIMOV. Le feu sacré. Paris. Fayard: 1985, p. 54.

7 L. Jakobson começou a trabalhar nos anos vinte. Seu Teatro de Miniaturas Coreográficas poderá enfim ser criado em 1970, mas fará apenas algumas apresentações esporádicas (Rodin, Cortejo de Bodas de Chagall, Contrastes - música de I. Stravinski -, Paolo e Francesca - música de A. Berg) até a sua morte em 1975. 


\section{Um tesouro perdido}

Nos grupos amadores que se dedicam à pantomima, totalmente ou em parte, a pesquisa de um saber do corpo aparece como a busca de um tesouro por duas vezes engolido: desaparecido, pela sua própria condição, com os atores que o colocavam em prática; e enterrado por subversão sob a primazia do texto afirmada na URSS desde 1927. Esta busca associa intimamente o treinamento, as influências estrangeiras, as leituras acadêmicas nas bibliotecas, a coleção de edições antigas e raras, assim como o recurso às artes plásticas. Ela reconstrói progressivamente toda uma filiação histórica que, a longo prazo, traz à tona as experiências da vanguarda russa e soviética nos anos 1910 e 1920 - as teorias de Delsarte expostas por S. Volkonski em 1912, Deburau, Chaplin, o Baptiste de J. L. Barrault e as tradições do teatro de feira das festas populares russas - saber colocado em evidência através de estudos científicos recentes ${ }^{8}$. Tesouro a redescobrir e a atualizar, a reintroduzir sobre, ou a substituir na cena dramática que se esvaziou, mais uma vez, do sangue das artes "menores".

O caso dos Litsedeï, amadores que se tornaram profissionais em $1979^{9}$, está dentro deste movimento. Viatcheslav Polounine, seu fundador, chega em 1967 em Leningrado onde segue uma dupla formação superior em economia e em história da arte, praticando, em grupo, a pantomima à noite, no antigo local de Slavski. Recusado no Instituto teatral por sua má dicção, ele se apaixona pelo trabalho de Marcel Marceau, desde a primeira vez que o vê na televisão em ocasião de sua primeira ida à URSS, em 1964, e em 1968 ele o segue passo a passo em todas as etapas de sua turnê. Através de seu programa com intuito pedagógico que retraça a história da pantomima, à qual ele se fez discípulo, Marceau o fornece uma "escola" e o permite compreender, concretamente, que é possível fazer teatro abolindo o texto.

A partir de uma longa e obstinada existência que distingue os Litsedeï de outros grupos, geralmente mais efêmeros ${ }^{10}, \mathrm{~V}$. Polounine se dedicou a reatar conjuntamente elementos divididos, a vida do grupo é tecida de encontros múltiplos que ele cita com paixão. Vontade de aprender, de colocar seus passos nas pegadas dos mestres distantes, de trabalhar a tradição para nela "reencontrar um fundo comum"11 aquele que ligaria o conjunto de uma cultura corporal geograficamente e historicamente dispersa, da pantomima do século XIX ao cinema das origens, da commedia dell'arte às entradas dos grandes clowns.

Os mestres? Certamente Chaplin, antes de tudo, e o cinema mudo, guardião dos traços dinâmicos do jogo/atuação, seja americano ou soviético (os filmes com Ilinski, este "Chaplin em uma armadura russa"); em seguida, Marceau e seu duplo, Bip com o rosto branco. O circo, e em particular o clown-poeta Leonid Engibarov, negro e magra figura de chapéu coco, com uma grande gola branca

\footnotetext{
8 Em Režisser zrelišča, op. cit. p.73, onde ele faz um balanço de sua atividade em Nach Dom, tece um elogio ao teatro de feira e uma análise da pantomima, M. Razovski cita, por exemplo, a tradução do livro de R. CHAUVIN. Le comportement des animaux / O Comportamento dos animais, Moscou, Mysl', 1972.

9 Eles adotarão este nome somente após o espetáculo Litsedeï em 1979.

10 É necessário citar o Ensemble du Drame/Conjunto do Drama plástico de Moscou, o qual se tornou profissional em 1976, dirigido por Gedrius Matskiavitchius, discípulo de M. Tennison, de inclinação mais coreográfica e que parte, para seus espetáculos, de obras picturais ou de textos literários (Blok, Aitmatov, Andersen, Pablo Neruda).

11 Odete ASLAN. Cirque et théâtre en France. in Du Cirque au théâtre. Textos apresentados por Claudine AMIARD-CHEVREL. Lausanne: L'Âge d'Homme, col. Th XX, 1983, p. 214. 
e uma longa gravata, acrobata-equilibrista que faz a "Entrada" do circo caminhar em direção ao teatro. Jacques Lecoq, o qual Polounine encontra em 1971, após a apresentação do espetáculo Histórias alegres e sérias/Histoires gaies et sérieuse (Novelly o smešnom i ser'eznom) no Havre, e de quem ele descobre o programa pedagógico ${ }^{12}$. Modis Tennison, cujos espetáculos são inspirados pelos quadros de Max Ernst, onde personagens fantásticos, metade homens, metade pássaros, interagem em um cenário cotidiano.

É através de Tennison que, aproximadamente em 1971, Polounine descobre o trabalho de Jerzy Grotowski, em seminários informais em Kaunas e através de traduções de artigos e de descrições de exercícios em samizdat (redes artesanais não oficiais de edição). Através de Tennison, sua comunidade teatral e da leitura de textos proibidos à publicação ${ }^{13}$, a lição de Grotowski conduz a "uma visão do teatro concebido não como uma representação das coisas, mas como uma exposição de si mesmo, na sinceridade, na abertura, na penetração, na maior tensão das forças na cena"14. Polounine detém esta noção de abertura que faz parte do vocabulário de Grotowski ${ }^{15}$, a criação de uma atmosfera de confiança em que o ator pode fazer tudo, à procura do contato com o público e de estimulações exteriores fecundas.

A influência de Grotowski na URSS, que será reativada em 1976 pela sua presença concretizada por intervenções, diálogos e debates no Festival de teatro e de dramaturgia polonesa em Moscou ${ }^{16}$, caminha desde já de modo indireto e misterioso, apoiada na oralidade, na lenda e na atração magnética de uma experiência forte, ausente em qualquer espetáculo apresentado na URSS. Mais do que a cartilha de seu ensinamento, o que permanece é a ideia do training colocada em prática da meIhor forma possível em todos os grupos e estúdios; é, sobretudo, a própria existência do homem de teatro Grotowski e a força do desafio da qual ele impregna o trabalho cênico: a entrega total de si mesmo na arte.

\section{Uma bricolagem de influências}

Encontra-se então em Polounine, como em outros grupos, uma rede de influências múltiplas, como uma bricolagem e superposição de impressões (overprinted), em razão das interdições de circulação dos homens, dos espetáculos e dos livros. Autodidata teatral, Polounine tem o olhar aberto, sobretudo para o que acontece ao

\footnotetext{
12 Ele vem à França convidado pela prefeitura de Havre, em acordo com Leningrado. A segunda parte do espetáculo é firmada por uma antiga aluna de Decroux, Yves Lebetron. Em Paris, então, Polounine encontra J. Lecoq.

${ }^{13}$ Aluno de I. Zavadski no GITIS de Moscou em 1955-1956, Grotowski é suspeito, na URSS, de "deformação sobre vanguardistas do sistema Stanislavski”. Ele publica textos em polonês a partir de 1965, os quais não são todos traduzidos em Towards a pour Theatre, Odin Teatrets Forlag, em 1968 e que foram reunidos em uma edição recente: J. Grotowski. Teksty z lat 1955-1956, editado por I. Degler ET Z. Osinski, Wroclaw, Université de Wroclaw, 1989. Alguns já puderam circular traduzidos do polonês para samizdat russa. Os exercícios foram traduzidos muitas vezes para o inglês. Duas pessoas tiveram particular contribuição na tradução e na circulação samizdat dos textos de Grotowski: Andreï Droznine ET Elena Khodounova. Na imprensa moscovita, entre 1971 e 1975, saem algumas raras traduções. A partir de 1987, as traduções são mais numerosas.

${ }^{14}$ Entrevista de V. Polounine, realizada por B. Picon-Vallin, Paris, novembro de 1989.

${ }^{15}$ Cf. Raymonde TEMKINE. Grotowski. Lausanne: La Cité L'Âge d'Homme. 1968, p. 141-142.

${ }^{16}$ Cf. M. ŠVYDKOJ. Peter Brook et Jerzy Grotowski in: Teatr, n.11, Moscou: 1988, p.100-118. A intervenção feita no VTO em Moscou, em novembro de 1976 no Symposium soviet-polonais / Simpósio soviético-polonês "Le monde doit être Le lieu de la verité/O mundo deve ser o lugar da verdade" foi publicado, somente, em 1987 (Teatral'naja žizn', n.24, Moscou, trad. A. Droznin). A partir de 1976, alguns contatos mais diretos foram estabelecidos (viagens de V. Fokine a Wrocllaw em 1976 e 1978, ct. V. FOKINE, Les leçons de Grotowski / As lições de Grotowski, in: Teatr, n.7, Moscou, 1990).
} 
seu redor - as encenações de Lioubimov, as técnicas de Arkadi Raikine no music-hall, o trabalho de Jakobson. Ele reporta-se à história teatral de sua cidade para chegar ao Estúdio de Meyerhold, à Comédia popular de Radlov, à FEKS, Fábrica do Ator Excêntrico. Ele se provê de documentação sobre a commedia dell'arte com os especialistas russos e soviéticos, K. Miklachevski, A. Djivelegov ${ }^{17}$ e, também, sobre o kabuki. Nesta situação de penúria cultural, uma estranha fotografia cortada por acaso em uma revista estrangeira, com expressivas silhuetas negras com chapéu em um fundo branco, tem um grande papel para o imaginário: trata-se da trupe de Pina Bausch, mas será somente mais tarde que Polounine poderá associar seu nome a esta fotografia, pois Pina Bausch viria à URSS apenas em 1989.

Dois elementos contribuem para a evolução da estética do grupo. Primeiramente o rock - fenômeno da contracultura e que por esta razão atinge amplamente grande parte dos grupos de teatro amadores: Polounine o caracteriza como um "golpe psíquico" que desestabiliza sua ideia do Belo, abalando as bases que repousam sobre o equilíbrio, a harmonia e a ordem. Em seguida o butô, apreendido através da leitura, no momento das primeiras turnês no exterior, o que aparece como uma nova etapa após Grotowski, em busca de uma maior liberdade interior. Contudo, o trabalho do grupo ainda responde mais a uma anima allegra, que ao aspecto "dança das trevas" existente em "A Vida dos insetos" (1985), dita "clowneria negra". Foi com um dos membros do Litsedeï, A. Adasinski, que, em 1986, ele se separará para fundar seu próprio teatro "Derevo" (A Árvore), com o qual expressarão as influências de Hijikata e do Sankai Juku muito diretamente nos corpos andróginos, desnudados, com a cabeça raspada, na agressividade das ações realizadas contra eles e a manipulação de matérias viscosas, objetos de repugnância.

Ao longo dos anos setenta, os Litsedeï se iniciaram em diversas disciplinas para as quais eles chamaram especialistas soviéticos: dança clássica, mas também jazzdance, yoga, karatê, zen. Existe uma grande vontade de reagrupar por aprendizagem de saberes dispersos e proibidos, ao mesmo tempo que estudar tudo o que é ligado ao movimento nas culturas ocidentais e orientais. Com a entrada de um surdo-mudo, S. Chacheliev, na trupe, uma etapa importante é atravessada: todos assimilam sua linguagem gestual, a qual é, ao mesmo tempo, precisa, concreta e imagética, e todos podem praticar com ele cotidianamente.

\section{Da pantomima à clowneria}

Durante dez anos, o Estúdio de V. Polounine acolhe, todas as noites, dezenas de membros, mas cada ano só ficam um ou dois novos atores. De 1969 a 1979, ele produz sete espetáculos ${ }^{18}$ compostos de esquetes sem palavras, as quais os tornarão conhecidos como os "mestres do riso"19. Em 1979, com a passagem ao profissionalismo, eles conseguem uma pequena sala no Palácio da Juventude de

\footnotetext{
${ }_{17}$ Muito jovem, Polounine não pode ver Marcello Moretti na turnê do Piccolo Teatro em 1960. Sobre a importância dessa turnê e do jogo em cena de Moretti, têm-se alguns testemunhos, em particular, aquele do ator Sergueï lourski - Kto deržit pauzy / Aquele que tem a pausa, Moscou, Iskusstvo, 1989, p.166. Polounine trabalhará, em meados dos anos oitenta com Angelo Corti. Do mesmo modo, ele verá o teatro kabuki somente em 1989.

${ }_{18}$ Ver, em anexo (nesta tradução, no final do artigo), a lista dos espetáculos dos Litsedeï, de 1969 a 1986, início do teatro de rua.

19 Cf. V. ŠČERBAKOV. À propôs du théâtre plastique. Art. cit. p. 33. 
Leningrado 20 . Progressivamente, eles pervertem as formas históricas da pantomima, passando das malhas pretas e sapatilhas brancas aos figurinos sarapintados, introduzindo objetos reais e sonorização. Os espetáculos têm subtítulos que tentam os definir: "parábola"; "revista esportiva"; "conto oriental"; "show"; "espetáculo-jogo"; "farsa" ou "teatro de feira"; "fantasmagoria excêntrica". Um trabalho feito por números permite uma certa independência com relação às partes censuradas (como aconteceu em Quadros de uma exposição, espetáculo com música de M. Moussorgski, em que a dança macabra do bêbado que zomba da sua amazona "morte", foi proibida, em 1980). Isto permite, também, o aprofundamento constante de sua pesquisa, além do sucesso popular, para o desenvolvimento de certos números e a integração destes no interior do espetáculo seguinte. Uma trupe se forma, onde cada um é capaz de fazer tudo, onde ninguém é estrela, onde a improvisação nasce do hábito de jogar/atuar juntos, das adaptações frequentes das criações aos diferentes espaços onde eles são convidados (music-hall, cena, picadeiro), da evolução dos números, do grau de entendimento com os parceiros de cena ${ }^{21}$. No dia $1^{\circ}$ de abril de 1988, esta trupe encena, nas ruas de Leningrado e às margens do Neva, seu próprio enterro, após vinte anos de existência, duração máxima para um teatro, segundo Stanislavski, momento carnavalesco que assegura a vitalidade do grupo.

Os Litsedeï evoluem da pantomima à clowneria, após, da clowneria ao teatro de rua, sempre se engajando em uma atividade de revelar, incitar, somar forças, apoiadas pela organização de muitos festivais concebidos como eventos-festas temáticas, obras teatrais em si, dentro da lógica de suas evoluções internas e de seus projetos pedagógicos. Assim em 1982, Mime-parade, manifestação semioficial apoiada pela organização dos Komsomols, reúne pela primeira vez, o pequeno grupo de cerca de quarenta trupes que praticam a pantomima na URSS e oficializa a passagem dos Litsedeï ao trabalho de clown. Em 1988, o Congresso dos Imbecis reuniu alguns clowns que colocavam o público em cena em um percurso-paródia do sistema burocrático impondo condições para a entrada: vestir um figurino-fantasia (gravata, chapéu), transpor cordas de marinheiros, se munir de carimbos/selos obrigatórios aplicados ironicamente, mesmo sobre a pele, encontrar a entrada do Palácio da Juventude no final de um itinerário complicado e absurdo já que todas as numerosas entradas estão fechadas (exceto uma) como acontece dentro de um lugar público soviético. Com o cortejo fúnebre e grotesco do enterro dos Litsedeï, este "Congresso" oficializa a saída da trupe na rua, o que já acontecia desde 1986.

Em 1981-1982, com a preparação do que será "Tchourdaki" (palavra inventada a partir de tcherdak (sótão) e tchoudak (original), ou seja "Originais em um sótão"), os Litsedeï vão cessar de insistir na precisão do gesto narrativo, descritivo e imitativo a que se dedicavam até então, em particular em "Fantazery" (Os Sonhadores) (1976) em que, ao redor de um banco, eles recriaram a liberdade do mundo imaginário da infância, vista como um estado de criação - alteradamente

\footnotetext{
${ }^{20}$ Dirigido pela VLKSM (União Pansoviética dos Komsomol de Lenin).

${ }_{21}$ Os elementos dados aqui sobre Tchourdaki dizem respeito ao espetáculo como foi apresentado em Paris, no Teatro de Ranelagh, em 1982. É necessário dizer que de uma noite à outra, o espetáculo muda, são pedaços de cenas acrescentados ou suprimidos, segundo as improvisações do dia e em função daquilo que eles perceberam que funcionou no espetáculo do dia precedente (cf. também infra, nota 30).
} 
viravam aviões, cosmonautas, macacos ou marcianos, como fogos de artifício que explodem em perseguições, brigas e ações. Eles param de insistir na filigrana do movimento, a virtuosidade do gestual não deve mais ser remarcada como tal. Eles dão prioridade ao seu valor emocional: o contato natural a estabelecer entre a cena e a sala [público] tem maior valor que a demonstração da maestria. Eles descobrem que se a pantomima, mesmo cômica, separa (admiração do espectador diante da superioridade técnica e estética do corpo do ator), somente a clowneria pode tocar e unir. Eles tratam, então, de reencontrar "o autêntico espírito do circo", feito de subversão, de lirismo e de grotesco tragicômico. A gestualidade deixa o domínio da descrição para tornar-se mínima, sugestiva, metafórica. Cada ator parte em busca de sua máscara de clown através de suas próprias características psicofísicas e os materiais iconográficos reunidos sobre os heróis do picadeiro. Aparece um gênero híbrido, em que o Grupo de pantomima Litsedeï é designado ainda por diferentes expressões: "Teatro dos clowns-mimos" ou "Teatro de improvisação dos corifeus". Quem eles são: mimos, clowns ou atores, eles que reivindicam fazer teatro?

"Tchourdaki"22 começa com uma sucessão de maquiagem na qual, lentamente, enquanto o público se instala, os atores se vestem e fazem suas "maquiagens" de clown, as quais eles tirarão no final: pasta branca, lápis preto, cabelos armados e perucas exageradas ou chapéus, narizes de plástico. Ao som de uma cantiga popular italiana Les canaris bleus/Os canários azuis, "arranhada" em uma língua internacional (trata-se de uma música que atravessou países e a gravação foi encontrada na Bulgária): um trio avança docemente, sequência onírica nascida desta música e da imagem que os Litsedeï têm dos três Fratellinis no Medrano, no início do século ${ }^{23}$. Estas três estranhas figuras mudas movem-se mexendo mal e mal os lábios na letra da canção um pouco vulgar e apertando, delicadamente, as laterais de suas concertinas fictícias sob uma chuva de minúsculas bolhas de sabão, as quais o maior, saltitando em contratempo com uma falta de jeito trabaIhada, tenta apanhar com uma rede de caçar borboletas... Colorido e extremamente frágil ao mesmo tempo, este trio, que reentra idêntico no final, completa a abertura do espetáculo em que os atores mostram suas transformações em personagens; ele introduz a dramaturgia do espetáculo composta de sequências combinadas segundo o princípio da montagem: dramaturgia fundada não sobre um texto, mas sobre a individualidade dos intérpretes e sua criação de personagens através de categorias sensíveis como o gesto, o movimento, o espaço, o figurino, a cor, o ritmo, o som. Livres do enquadramento textual, os Litsedeï têm à sua disposição uma ampla gama de meios de inventar, não somente sketches e números, mas todo um espetáculo construído sobre uma dramaturgia onde o corpo não é nem o dispositivo, nem o suporte da criação teatral, mas o centro, material autoreferencial e autônomo que funciona sobre dois princípios: o jogo como meio de existência, e a máscara.

\footnotetext{
${ }^{22}$ O espetáculo é considerado como um dos melhores de Leningrad de 1983-1984.

${ }^{23}$ O livro do P. MARIEL. Les Fratellini: Histoire de trois clowns. Paris: 1923 - foi traduzido para o russo em 1926. 


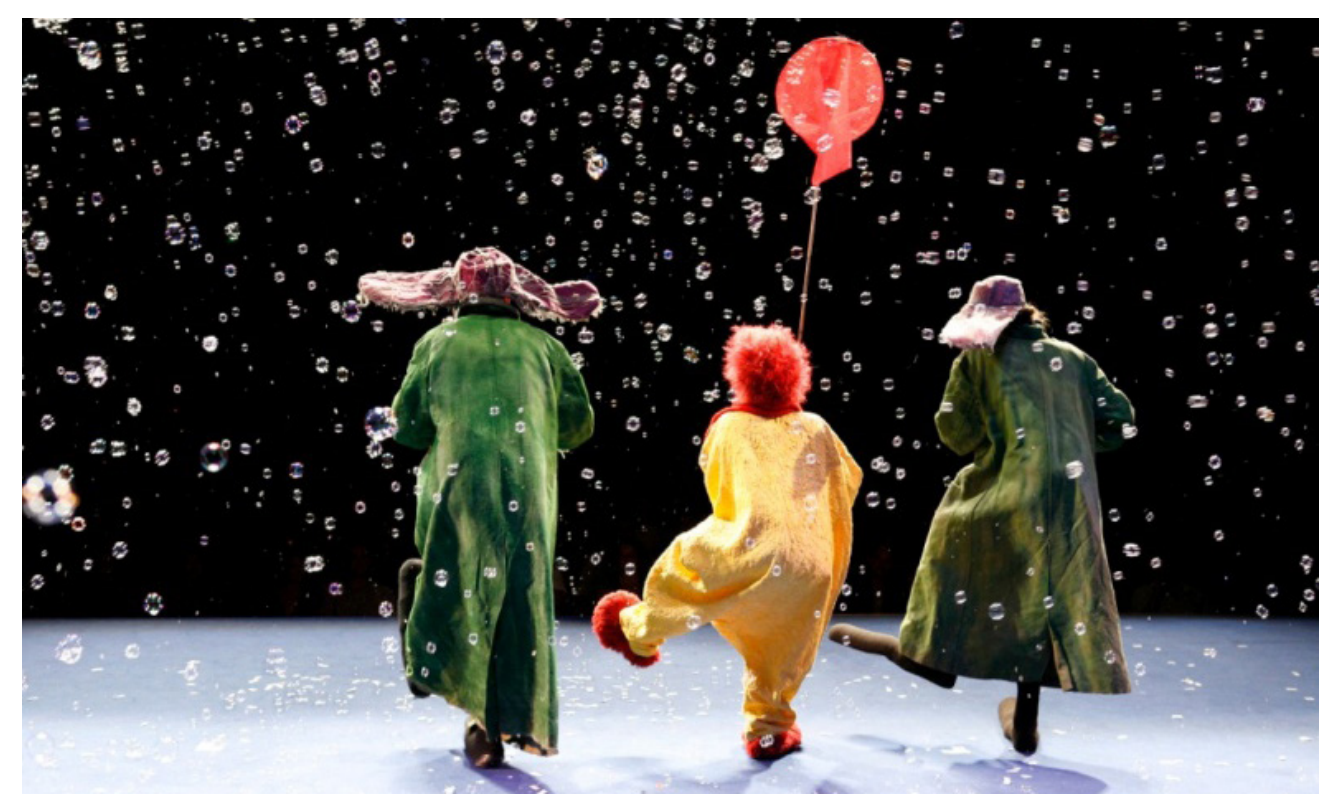

Figura 1 - Espetáculo: SlavaSnowShow (número Bleu Canaris), Temporada no Théâtre Casino, em Paris. Foto: sem indicação do autor. Cortesia de SlavaSnowShow. Direitos Reservados.

Rejeitados em um sótão, os clowns, uma vez celebrados, continuam jogando entre eles, com os entulhos do sótão, com os espectadores. Lugar que é ao mesmo tempo metafórico, ficcional e real, receptáculo da memória dos corpos esquecidos da cena, do picadeiro ou do cinema mudo, espaço unificador do espectador e depósito de acessórios e figurinos da trupe de hoje, este sótão possui, ainda, o mundo e o universo sob a forma de bolas e esferas, de diferentes tamanhos e cores, suspendidas. Se desenvolvendo entre estes quatro planos espaciais, "Tchourdaki" nada mais é do que o próprio caminho dos Litsedeï na história dos espetáculos, à procura das raízes, através dos gêneros heterogêneos e a evolução contínua de personagens cuja relação levada à público é feita de reconhecimento, familiaridade (Pierrot, Carlitos) e espanto (estranhamento).

Neste espaço onde estão acumuladas as velhas e heteróclitas bagagens dos vagabundos do teatro - mala, caixotes, baú, lata, balde, carro de criança -, os objetos mais banais se transformam, segundo o método poético da realização da metáfora ou como ponto de apoio de um jogo contínuo que os atribui sucessivamente várias funções e sentidos: uma vassoura vira bengala de cego, pá de coveiro ou remo; uma pedra, comida fumegante ou peça de xadrez; uma raquete, bebê, navalha ou machado de carrasco; uma mala, mesa de maquiagem ou barco.

A gênese dos personagens os situa na confluência do individual, da história dos espetáculos, da realidade social. Cada clown encontrado é como o duplo do ator, projeção plástica e rítmica hiperbólica de sua personalidade psicofísica em um palco que tem um rico passado e diante de um público que tem uma atualidade. Assim, um deles ${ }^{24}$, segundo o modelo de Albert Fratellini, tem uma personalidade extremamente ativa e curiosa, em relação a tudo. Ele tem os cabelos loiros, o olhar redondo e espantado, e usa um largo macacão xadrez, com bastante enchimento. Pegou

${ }^{24}$ L. Leïkine chegou na trupe após Thourdaki: seu personagem, então, foi introduzido na sequência do espetáculo. 
emprestado do tipo do "clown-vagabundo", uma maquiagem em forma de barba negra - sinal de desleixo -, aplicada ao redor da boca até as orelhas. $O$ ator precisou desse elemento de contraste, de oposição, para criar uma tensão, em relação a sua própria personalidade risonha e ensolarada, e fazer seu clown viver. S. Chacheliev (o surdo-mudo) dá vida a um novo augusto, criatura quase beckettiana: pequeno, cabelos longos, um grande casaco marrom esfarrapado, tênis em mau estado e um chapéu de papel bouilli25... Uma maquiagem branca com os lábios aumentados por um retângulo preto sublinha a distância entre os olhos trágicos e um grande nariz batatudo vermelho. Obcecado em desinfetar o sótão, ele persegue poeira e piolhos com a ajuda de uma vassoura e um poire à poudre ${ }^{26}$ e organiza, na mini-pista de uma lata, um combate de baratas que evoca Calvero e suas pulgas adestradas no filme "Luzes da Ribalta". Ao longo da representação, ele é, em sua vulnerabilidade, uma força de vida: mesmo intimidado, sufocado, ele se reergue obstinadamente após ter sido vencido, vai em frente, vive, apesar de tudo. Diante do poder militar, suas mãos executam uma dança perturbada, em que elas tentam resistir, obedecer desajeitadamente antes de executar corretamente a saudação exigida.

Quanto ao clown branco ( $N$. Terentiev), ele multiplica os papéis com alguns acessórios: cantor brega, chinês, empregada doméstica ou esposa hierática. Uma farda militar colocada nos ombros e ele constrói um personagem de ditador sob a impressão sonora da gravação de um discurso hitleriano sem sentido, mas identificável ritmicamente, sobre o qual ele dá alguns rugidos. Uma pequena bola suspensa a sua frente vira um microfone, depois, começa a girar sob sua respiração que se amplifica, mostrando, de vez em quando, a imagem do mundo em seu poder, como aquela do Chaplin-ditador. Enfim, Assissaï (V. Polounine), assim chamado por causa dos sons que ele emite em uma das sequências que fez muito sucesso, veste um macacão amarelo, uma echarpe vermelha, pantufas vermelhas felpudas enormes e, sobre sua maquiagem branca, contornada com uma linha preta em forma de coração que aumenta as sobrancelhas e afina o queixo, ele coloca um nariz cilíndrico. Rosto pensativo, intenso e terno sob uma cabeleira arrepiada, corpo desajeitado, cores gritantes e alegres, pequenos movimentos sutis, ele mora em uma mala de vime, vive nos sonhos. Na sua gênese, ele corresponde à atmosfera de paralisia social do período de estagnação.

Alguns anos mais tarde, em 1985, em "Assissaï-revue", este clown acabará por agir: perseguido por um partner que o proíbe de tudo, falando com voz nasalada, a cada passo ou gestos esboçados, a palavra nelzia ("proibido"), ele decide, enfim, agarrar uma grande bola cobiçada e o pontapé que ele dá mandando-a para a plateia, é o equivalente dinâmico da exclamação zia que ele grita simultaneamente - palavra inventada, fabricada com a retirada do sufixo privativo do termo precedentemente repetido. Esta inocente declaração de liberdade lúdica é imediatamente compreensível e colocada em prática ${ }^{27}$. A palavra-movimento age por contaminação sobre o público que devolve a bola, e depois, a partir desse impulso, joga com outras bolas, enormes e leves, lançadas do palco para amplificar o alcance desta curta e forte sequência. Um pequeno gesto simples e que

\footnotetext{
${ }^{25}$ Nota da tradutora: carton bouilli é uma técnica de cartonagem.

${ }^{26}$ Nota da tradutora: poire à poudre é um frasco de couro, com o mesmo formato de um cantil feito em couro. Era usado para carregar e guardar a pólvora utilizada para recarregar os fuzis.

${ }^{27}$ Este tema de interdição, de confinamento dos seres foi, durante muito tempo, trabalhado pelos Litsedeï em forma de pantomima, de um modo bem menos expressivo: um homem que quer atravessar uma rua e é constantemente impedido pelo apito de um policial-Deus - impossível de avançar, correr, rastejar etc.
} 
parece fácil, em uma breve sílaba, grandes efeitos...

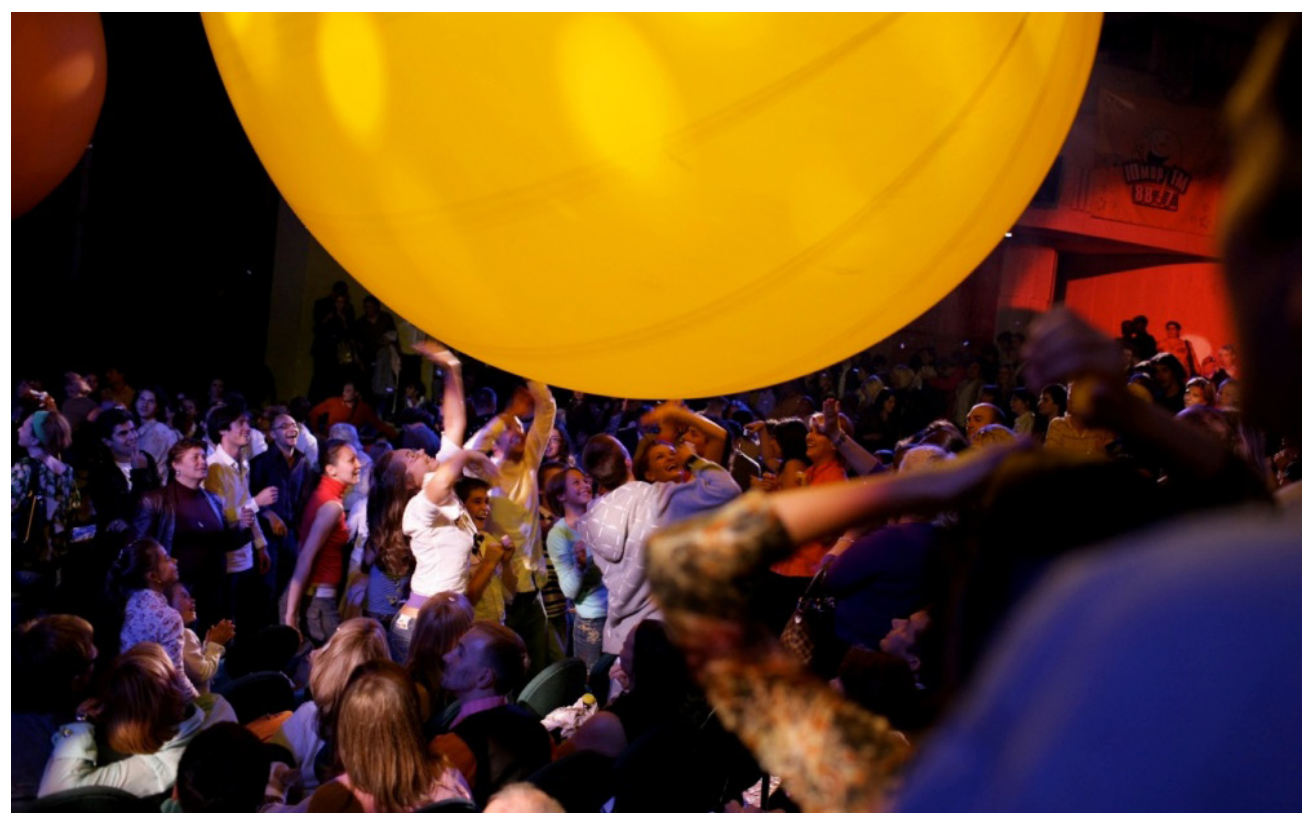

Figura 2 - Espetáculo: SlavaSnowShow, Temporada no Théâtre Casino, em Paris.

Foto: Bèatrice Picon-Vallin.

Sempre agressor ou agredido, dentro de situações conflituosas baseadas nas relações de força ou de poder, o corpo pode ser, no jogo, fragmentado, robotizado, carnavalizado, ele pode virar manequim, marionete ou objeto. Ele pode, também, na sequência que segue ao envio da bola e durante a troca ativa da cena e da sala (Assissaï-revue), voar $^{28}$.

Se, em um filme de F. Fellini, "Os Clowns", os Fratellini se erguem no ar, munidos de asas de borboleta, o clown voador pendurado pela cintura na ponta de uma corda em cima da plateia que reage animadamente, agitando-se e rindo, é aqui uma figura construída sobre o personagem coletivo, cotidiano e simbólico ao mesmo tempo, de uma velha com sacolas de provisões feitas de rede: que pode ser a "mãe-Rússia" da tradição, mas também o conjunto destas mulheres soviéticas sobre quem repousa a sobrevivência material do país. Interpretada por um homem, como todos os papéis femininos nesta trupe, "ela" move suas sacolas como se fossem asas, eco cômico do trapezista do picadeiro. A plateia joga com a velha senhora atarefada que plana sobre ela, a qual virou aérea apesar de tudo o que a liga ao solo. O corpo carnavalesco e a euforia anárquica do jogo passam a alternar do modelo chapliniano e da sua caça à felicidade para o dos Irmãos Marx, com uma busca voluntarista de liberdade. A partir de 1986 se abre diante dos Litsedeï o espaço da cidade, da rua, o lugar que vai permitir investir na experiência do trabalho sobre o corpo, do personagem, da improvisação e do público.

\footnotetext{
${ }^{28}$ O voo do palhaço não foi possível em todas as salas em que se produziu Litsedeï, uma vez que é necessário um equipamento especial.
} 


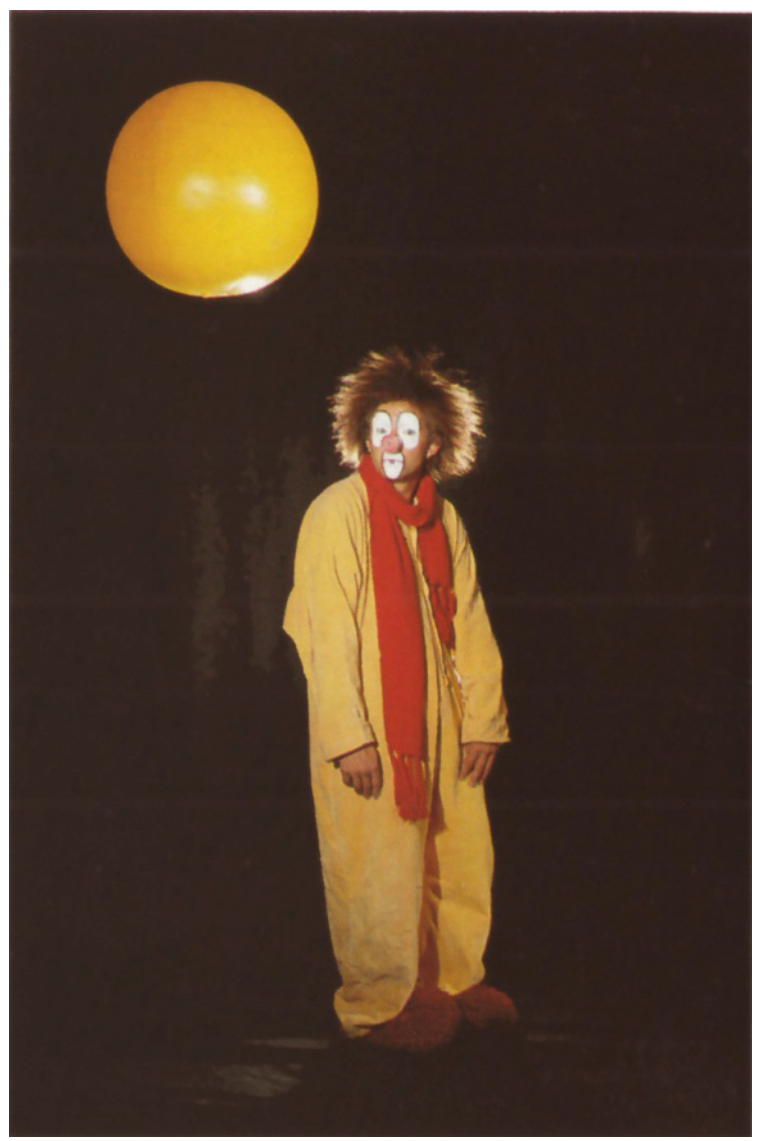

Figura 3 - Slava Poulunine. Espetáculo SlavaSnowShow. Foto: sem indicação do autor. Cortesia de SlavaSnowShow. Direitos Reservados.

Por mais opostos que sejam, estes dois exemplos extremos de modalidades de existência do corpo na cena soviética dos anos 1970-1985 aparecem, antes de tudo, como governados por um instinto de obstinada sobrevivência individual e afirmação do humano contra o ideológico, fora de qualquer compromisso político. Este corpo coloca em crise o texto teatral, seja pela oralidade inventiva de uma língua da necessidade, da urgência, do grito ("infralíngua"), seja pela supressão pura e simples da escolha do mutismo, seja, ainda, pela sua negação ("contralíngua") quando, nas intervenções verbais pontuais, a palavra deformada, inventada, transposta ou manipulada vira um acessório da cena, da mesma forma que os objetos ${ }^{29}$. Por ter sido violentado, eliminado, intimidado, humilhado, engolido por modelos coletivos e um sistema de penúria, por ter sido negado ou ocultado, tanto como realidade quanto como meio artístico, ele está ligado a um fenômeno de ressurgimento, de reaparição. Sujeito da dramaturgia ou mesmo matéria prima do teatro, ele é, enfim, na sua decadência extrema, sua solidão, pela sua vida de necessidades e a cultura tragicômica a qual é ligado, a condição de um encontro, de uma relação que se quer autêntica com um público chamado a reagir.

\footnotetext{
${ }^{29}$ Em Tchernobyl-Catastrophe (Crondstadt, Aurillac, 1988) espetáculo de rua, os atores, alternadamente, pronunciavam no microfone, como os comentaristas esportivos, uma enxurrada de palavras ininterruptas, em várias línguas, justapostas, sem nenhum senso. 


\section{Anexos}

Lista dos espetáculos até 1986, início do teatro de rua:

- 1969 - "Histórias cômicas e sérias" ("Novelly o smešnom i ser'eznom”), pantomima-concerto;

- 1972 - "É preciso amar os pedestres" ("Pešehoda nado ljubit”) (com o Music-Hall dos Jovens);

- 1974 - "Mimimprovizy", parábolas;

- 1976 - "Os Sonhadores" (Fantazery), espetáculo-jogo;

- 1976 - "Pequena Olimpíada" ("Malaja Olimpiada"), revista esportiva;

- 1977 - "Tek-Chen, o homem de pedra" (“Tek-Šen, čelovek iz Kamnja”), contos orientais;

- 1979 - "Litsedeï” (“Licedej”), história para teatro de feira com garras e beijos;

- 1980 - "Quadros de uma exposição" (“Kartini s vystavki”), música M. Moussorgski;

- 1981 - "Uma noite na montanha Careca" ("Noč’na lysoj gore”) fantasmagoria excêntrica;

- 1981 - "Show ol" ("Sou-Ol”), programa realizado com os autores satíricos;

- 1982 - "O Garoto" - Kibaltchich" ("Mal'čik - Kibal'ciš") musical infantil com l'Ensemble Raduga;

- 1982 - "Tchourdaki” (“Čurdaki”), clowneria;

- 1983 - "Petrouchka" ("Petruška"), jogo teatral;

- 1984 - "Assissai-revue" ("Asisjaj- revju”), clowneria lírica;

- 1985 - "A Vida dos Insetos" (“Žizn' nasekomyh”), clowneria noire;

- 1985 - "Sonhos", não-espetáculo;

- 1986 - "A Volta ao mundo", jogo-conto de fadas sobre a água;

- 1986 - "Aviação", performance-catástrofe de rua.

\section{Referências}

ASLAN, O. Cirque et théâtre em France. In: Du Cirque au théâtre. Lausanne: L'Âge d'Homme, col. Th 20, 1983.

CHAUVIN, R. Le comportement des animaux. Moscou: Mysl', 1972.

FOKINE, V. Les leçons de Grotowski. In: Teatr., n.7, Moscou, 1990.

LES VOIES de la création théâtrale. Paris: Edições do CNRS, 1984. (Coleção Arts du Spectacle, V. 12).

LIOUBIMOV, I. Le feu sacré. Paris: Fayard, 1985.

MARIEL, P. Les Fratellini. Histoire de trois clowns. Paris, 1923.

MARKOVA, E. M. Marceau. Leningrado: Iskusstvo, 1975.

ROZOVSKIJ, M. Režisser zrelišča. Moscou, 1972.

ŠČERBAKOV, V. À Propos de théâtre plastique. In: Teatr, n. 7, Moscou, 1985.

ŠVYDKOJ, M. Peter Brook et Jerzy Grotowski. In: Teatr, n.11, Moscou, 1988.

TEMKINE, Raymonde. Grotowski. Lausanne: La Cité L'Âge d'Homme, 1968. 